\title{
Um novo espírito teatral carioca: entre televisão, patrocínio e política
}

\author{
A new Rio theatrical spirit: between television, \\ sponsorship and politics
}

\section{Gustavo Guenzburger}

Gustavo Guenzburger

Ator, diretor e produtor de teatro. Pósdoutorando em Artes Cênicas no PPGAC da UNIRIO, com supervisão da Profa. Dra. Maria Helena Werneck

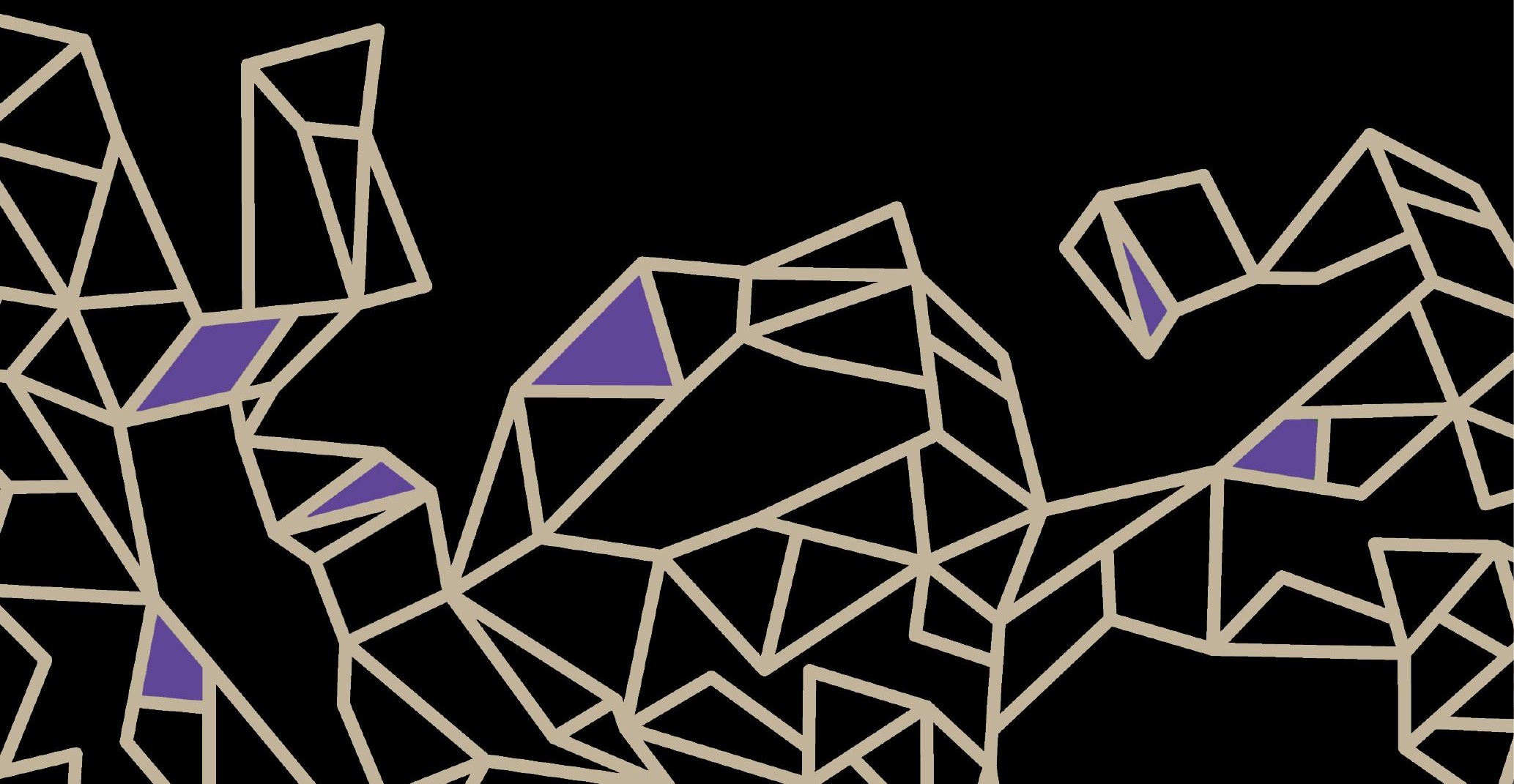




\section{Resumo}

Este artigo tem por objeto as relações entre a estética e a socioeconomia de parte do teatro carioca contemporâneo, no contexto do início de uma pesquisa de pós-doutorado em que novas poéticas teatrais são estudadas junto a seus novos modos de produção. São analisadas aqui, pela primeira vez, as possibilidades de interação estética entre as forças do patrocínio e da televisão dentro da cena contemporânea carioca. A partir deste e de outros contextos, surgiria um "novo espírito teatral carioca", responsável por viabilizar ideologicamente a existência do teatro experimental pela práxis do artista-empreendedor. A hipótese formulada abrange, no campo estético, uma vertente carioca paradoxal, em que representações conservadoras de "figuras humanas medianas" e "naturais" habitariam dispositivos cênicos altamente inovadores, tanto como expediente criativo quanto como possível resultado do jogo de forças de delimitação social no campo teatral da cidade.

Palavras-chave: Teatro contemporâneo, Sociologia teatral, Artista-empreendedor, Televisão, Patrocínio.

\section{Abstract}

This article focuses on the relationship between the aesthetics and the socioeconomics of the contemporary theater of Rio de Janeiro, Brazil, in the context of the beginning of a post-doctoral research in which new theatrical poetics are studied along with their new modes of production. The possibilities of aesthetic interaction between the forces of sponsorship and television within the Rio contemporary scene are analyzed here for the first time. From this and other contexts would emerge a "new Rio theatrical spirit", responsible for ideologically enabling the existence of experimental theater through the praxis of the artist-entrepreneur. The hypothesis formulated covers, in the aesthetic field, a paradoxical Rio trend, in which conservative representations of "natural" and "average human figures" would inhabit highly innovative scenic devices, both as a creative expedient and as a possible outcome of the game of social demarcation forces in the theatrical field of the city.

Keywords: Contemporary theater, Sociology of theater, Artist-entrepreneur, Television, Sponsorship. 


\section{Introdução: contexto histórico e de pesquisa}

Apesar de o teatro ser uma arte que, desde seu início, quase sempre se viu às voltas com o mecenato, na contemporaneidade brasileira esta questão torna-se tanto mais definitiva quanto complexa. Dos anos $1990 \mathrm{em}$ diante, objetos de arte de qualquer custo começaram a ter que ser previamente planejados para passar pelo crivo dos setores de marketing, outras vezes pelas comissões de julgamento, e sempre por meses de trâmites burocráticos. Seja para agradar ao empresário, ao governo, ou a ambos, esse planejamento, que é um narrar-se antes de existir, não é efetuado pelo artista, mas pelo produtor cultural - ainda que às vezes eles sejam a mesma pessoa -, e deixa marcas indeléveis no produto artístico final. No mundo inteiro, aspectos teóricos da produção e da recepção desta "arte por projetos" estão sendo estudados (SMARTBE; BAYER, 2011). Quando o produtor narra e planeja a obra antes de contratar os artistas que irão criá-la, quem é o sujeito da criação? E o do discurso? Quando o consumidor de arte já não é mais o seu financiador, quem é o público-alvo? E no caso singular da distorcida legislação cultural brasileira dos $100 \%$ de incentivo fiscal, na qual o mecenato é dividido entre alguém que decide, mas não paga (a iniciativa privada), e alguém que paga, mas não decide (o governo brasileiro), qual mecenas deveria ficar satisfeito com o resultado da obra e de que maneira? E, principalmente, quais estéticas e quais discursos são mais valorizados ou mesmo autorizados a emergir dessas novas formas de produção?

Baseado em estudos de casos históricos e em discussões teóricas, analisei em minha tese de doutorado algumas dessas relações entre a estética, a produção e a recepção de uma vertente histórica do teatro produzido no Rio de Janeiro, que se propõe manter-se além do entretenimento. $\mathrm{O}$ critério para a escolha dos casos estudados foi o da inteligibilidade das relações entre estética e contexto socioeconômico, a partir de minhas próprias referências e vivências enquanto também artista e produtor teatral. A abordagem do teatro como fenômeno artístico-cultural, que interage com o meio socioeconômico, valeu naquele trabalho tanto para o teatro da contemporaneidade quanto em suas discussões históricas dos últimos 60 anos. A universalização da TV, a falta de público pagante para a arte e a ainda recente e incipiente resposta 
do Estado como financiador universal da cultura apareceram ali intimamente ligadas à proliferação e transformação de poéticas teatrais, principalmente no que concerne ao trabalho do ator em cena, sua formação, e a concepção que ele tem de sociedade e de seu papel dentro dela. Esta mirada, a partir do fazer e da recepção teatral, questiona o valor de limites fixos entre arte e indústria cultural, ao assumir como problemática a definição de arte e cultura na contemporaneidade.

Se, em todas as regiões do Brasil, o surgimento recente de novas formas de fomento permite uma aceleração da produção artística, especialmente a de caráter experimental, pelo menos no Rio de Janeiro esta vem acompanhada do descompromisso com o sustento de uma grande parte de seus artistas. A parcela do teatro carioca que não se define como entretenimento veio perdendo público, a ponto de se equiparar ao esquema dependente de mecenatos e curadorias que até então sempre fora o da dança, da ópera e das artes programadas em galerias e museus. Hoje, apesar dos muitos espetáculos de teatro em cartaz, não há plateia suficiente para o financiamento por bilheteria. Dada essa situação e a inconstância e a incerteza dos patrocínios, uma fatia dos trabalhadores da chamada "classe teatral" sobrevive principalmente de expedientes como carreira acadêmica, biscates ou trabalhos em TV, salas de aula, lojas, produção de festas, peças "comerciais", entre outros, mas raramente de sua atividade artística ${ }^{1}$. Guardadas as devidas exceções e interseções, surge deste diagnóstico a hipótese de o teatro carioca viver uma volta à divisão "pré-moderna" em duas formas de produção: de um lado, os grupos e produções semidiletantes do teatro "sério" - agora experimental, de novas linguagens -, e do outro, uma indústria sustentável do teatro cômico, do musical e de artistas famosos - agora televisivos (GUENZBURGER, 2012a, 2015a).

No doutorado pude verificar que, na segunda metade dos anos 1980, algumas das primeiras peças patrocinadas pelo sistema de mecenato de certa forma reagiram àquele novo momento de concorrência desigual com as novelas televisivas ao proporem estéticas pós-modernas e autorreferenciais, voltadas para a busca de novas linguagens e baseadas na criatividade do encenador. Embora as novas cenas ajudassem a criar uma certa autonomia

1 Segundo o PNAD de 2004 do IBGE, a taxa de trabalho sem vínculo empregatício no setor das artes e espetáculos era de $84,48 \%$, contra $40 \%$ em outras áreas (IBGE, 2004). 
artística para a parte mais experimental do teatro carioca, também inauguravam a lógica de financiamento e legitimação curatorial, cujo deslocamento de foco, do público para o patrocinador, aumentava ainda mais o problema das bilheterias no Rio de Janeiro. Nos anos 1990, o surgimento de uma rede municipal de teatros na zona sul e no centro e de lonas culturais em áreas mais pobres, junto com o fortalecimento dos sistemas SESC/SESI de cultura, tentou acompanhar o interesse de novas gerações e novas camadas da população por um ofício teatral cada vez mais precário, cujo número de profissionais registrados se expandia na proporção inversa de seu público pagante tradicional da classe média.

A partir dos anos 1990, aos poucos a novidade midiática dos "grandes encenadores" foi perdendo fôlego no Rio, e a tarefa de descobrir novas linguagens para os palcos da cidade foi sendo gradativamente dividida com grupos e companhias que, desde a década anterior, surgiam como alternativa ao esgotamento do mercado de teatro por bilheteria e como contraponto artístico ao sistema de estrelato. Por isso mesmo, tiveram que fazê-lo também à margem do mecanismo instaurado pela Lei Rouanet, cuja lógica do retorno de marketing acabou causando, com o tempo e especialmente no teatro do Rio, um direcionamento mais mercadológico para o mecenato. Com a institucionalização do incentivo fiscal, as empresas patrocinadoras foram abandonando gradativamente o gosto inicial pela novidade artística das estrelas da encenação para abraçar de vez a visibilidade do star system dos atores televisivos e o sucesso da indústria de musicais.

De 1999 a 2002, o movimento "Arte contra a Barbárie" havia lutado em São Paulo contra esse quadro de mercantilização do teatro (DESGRANGES; LEPIQUE; CPT, 2012). O "Fórum das Artes - Rio", menos politizado e mais pragmático do que seu inspirador de São Paulo, juntou o segmento dos grupos a outros, em janeiro de 2003, na reivindicação de políticas públicas de fomento para as artes cênicas no Rio de Janeiro. Mas, ao contrário do paulista, o movimento carioca não emplacou uma lei municipal e nem focou no trabalho continuado de grupos. Mesmo assim, sob sua pressão foi elaborado, naquele mesmo ano, o primeiro edital da prefeitura para a produção teatral, o chamado Fundo de Apoio ao Teatro. Se o primeiro FATE iniciou uma série que não chegou a criar uma estabilidade para o setor de pesquisa cênica, 
consolidou a sistematização do patrocínio com algum privilégio para as novas linguagens, ao mesmo tempo que lançou esse segmento definitivamente na lógica dos projetos de curto prazo, e praticamente silenciou suas reivindicações pelos dez anos seguintes.

Durante esse período, apenas a AGC (Associação de Grupos e Companhias de Teatro do Rio de Janeiro) chegou a se organizar e representar em parte o setor da experimentação teatral, como contrapeso da criação da APTR (Associação de Produtores de Teatro do Rio de Janeiro), cujos integrantes, de maneira geral, ocupam-se mais com a produção viabilizada mercadologicamente por apelo midiático e mecenato incentivado. Mas depois de algum tempo e na falta de uma política cultural para trabalhos continuados de médio e longo prazo, como aquela estabelecida pela Lei de Fomento em São Paulo, os próprios grupos teatrais cariocas também começaram a se adaptar à lógica de produção por projetos, transformando-se aos poucos em núcleos ou empresas especializadas na concorrência em editais. Essa mutação na forma como toda uma geração de coletivos passou a encarar seu próprio trabalho transformou a associação de grupos em uma representação inócua e sem sentido. O fechamento da AGC em 2008 selou, para o segmento do experimento teatral carioca, sua opção pelo empreendedorismo e a volta de seu silêncio político, rompido apenas na eclosão do movimento "Reage, Artista!", cinco anos depois².

\section{Um novo espírito e a hipótese do paradoxo teatral carioca}

Sociologicamente falando, o que minha pesquisa de doutorado identificou sobre a parte do teatro carioca produzida nas redes públicas dos teatros da zona sul e do centro - com verbas geralmente obtidas em editais de fomento e que se liga de uma forma ou de outra à pesquisa de novas linguagens cênicas - foram forças que a empurram na direção do que Luc Boltanski

2 O movimento "Reage, Artista!" foi criado no início de 2013 por artistas e agentes de cultura como uma reação ao sucateamento dos teatros, bibliotecas e outros equipamentos culturais, que a prefeitura do Rio havia fechado em resposta à tragédia da boate Kiss, em Santa Maria (RS). O "Reage" criou então um espaço para o debate político dos trabalhadores da cultura que antecipou e, por fim, se somou à onda de protestos daquele ano, e continua sendo, ao lado de outros coletivos, uma referência na discussão de políticas públicas para a cultura na cidade. 
e Ève Chiapello (2009) chamaram de "o novo espírito do capitalismo". O que esse mercado restrito espera de um aspirante, para poder aceitá-lo, é que ele seja um artista-empreendedor, capaz de aproveitar as oportunidades do mercado e de projetar com clareza suas obras antes de criá-las, demonstrar o ineditismo e a criatividade de seu trabalho antes mesmo de ele existir; que trabalhe bem em equipes cujos integrantes podem ser trocados a cada nova empreitada; um artista capaz de forjar sua própria rede de relacionamentos e de divulgação, indispensáveis neste meio individualista e extremamente competitivo, que funciona por projetos, e no qual as maiores barreiras a serem vencidas são a do anonimato e a da falta de contatos e comunicação.

As forças mais atuantes no desenho deste novo perfil para o artista de teatro carioca parecem ser a lógica do patrocínio e o paradigma da televisão. Ambas são forças heterogêneas, e possuem cada uma delas diversas vertentes, direcionamentos, gradações e especificidades de nichos, mas também são ambas ancoradas na extrema competitividade de mercados saturados. No entanto, o mais importante durante minha pesquisa de doutorado foi perceber que esses dois polos demonstraram, até aqui, dialogar de maneira conjunta com o teatro, inclusive esteticamente, o que poderia ajudar a iluminar determinados fenômenos ou tendências observáveis em espetáculos cariocas contemporâneos. Estas ficaram apenas esboçadas em um "epílogo" de minha tese de doutorado, à espera de verificação e discussão posterior. Agora elas compõem o escopo de minha pesquisa de pós-doutorado, como campo de trabalho e como quadro hipotético inicial, cujo resumo apresento a seguir.

O estudo de alguns casos históricos na França e no Brasil tem demonstrado em minha pesquisa que a influência exercida pelo patrocínio estatal tende a favorecer o surgimento de novas linguagens, novos dispositivos cênicos. A ideologia que justifica esse favorecimento se enraíza na própria escala utilizada pelas instâncias patrocinadoras para qualificar e hierarquizar os projetos artísticos. Seja entre as gerências de marcas das empresas pioneiras no mecenato teatral dos anos 1990 - que hoje, "turbinadas" pela Lei Rouanet, só patrocinam experiências "já comprovadas" -, seja nas comissões de editais públicos do século XXI, a novidade cênica é sempre o critério artístico principal para a escolha dos projetos a serem patrocinados. Claro que a este critério se somam e se encaixam outros, mais socioculturais, que podem ter maior 
ou menor peso, dependendo de cada tipo de seleção: pertinência temática, currículo ou celebridade dos artistas, "impacto", abrangência ou alcance social, acessibilidade, potencial midiático, custo relativo, custo absoluto, etc. A pesquisa das estratégias utilizadas pelos projetos para se encaixarem nesses critérios promete ainda ser reveladora dos condicionantes estéticos, sociais e econômicos no teatro contemporâneo.

Por outro lado, a parte histórica de minha tese também investigou a forte influência e o diálogo que o teatro carioca tem travado desde a década de 1950 com a linguagem televisiva, ora rompendo com ela, ora explicitando o que ela esconde, ou ainda assumindo suas formas. O naturalismo da interpretação televisiva brasileira foi visto ali, em linhas gerais, como uma tendência de recalcamento de emoções, que tenta disfarçar ou dissimular o caráter melodramático da teledramaturgia nacional, dando-lhe um ar de modernidade e racionalidade (GUENZBURGER, 2015a, p. 52-73). Foi indicado na tese que, a partir do final dos anos 1980, várias correntes de experimentação teatral tentaram buscar em formas arcaicas ou tradicionais o contraponto para a invasão do paradigma do naturalismo "global" nos palcos. Alguns espetáculos nessa linha foram então citados, e depoimentos de atores e diretores confirmaram essa preocupação da classe teatral entre o final da década de 1980 e início de 1990. De lá para cá, embora esse movimento de pesquisa atorial de formas antigas, tradicionais, circenses ou alternativas pareça ter perdido destaque na cidade, as experiências que ainda persistem nesse sentido possuem caráter de longo prazo e uma grande propensão a romper com o modo natural de atuação, ao propor novas formas corporais e performáticas, na parte do teatro carioca que gira em torno do circuito de verbas e espaços públicos ${ }^{3}$.

Entretanto, nesse mesmo circuito parece haver hoje outra importante vertente estética, observável em muitos trabalhos inovadores e instigantes da cidade. Essa outra possibilidade artística diz respeito a uma defasagem que poderia ser distintiva na cena carioca contemporânea: a renovação da lingua-

3 São alguns exemplos o trabalho de Julio Adrião, de companhias que pesquisam a partir de máscaras, como os Bondrés, grupos de performance e teatro de rua, como a Cia de Mystérios e Novidades, e os que misturam circo e teatro, como o Teatro de Anônimo. Embora estes últimos atuem mais do centro para as zonas norte e oeste e fora do Rio. 
gem cênica no Rio de Janeiro parece, muitas vezes, deixar de lado o próprio trabalho de atuação.

Diretores, dramaturgos e grupos focalizam cada vez mais sua criatividade na invenção de novos e inusitados dispositivos cênicos, que podem incluir formas impensadas de narrar, de iluminar, de desconstruir estereótipos, de usar um palco ou de não usá-lo, de criar cenários mutantes, projetados, microfonados e sampleados ou não, de filmar a peça ou encenar o filme, de improvisar, fazer talk show, aula sobre a própria peça, fiç̧ão científica, peça virtual ou troca de sexo dos personagens. No entanto, muitas vezes não se espera ou se exige que o trabalho dos atores acompanhe as inversões de perspectiva desta miríade de dispositivos, mas simplesmente que os intérpretes se movimentem entre eles e os integrem com a maior naturalidade possível, podendo ser, inclusive, falando ao celular, tomando whisky ou fumando um cigarro. No Rio de Janeiro, o compromisso com uma verdade plausível, trivial e, muitas vezes, bem-comportada das personagens ou figuras do palco parece conviver bem com as mais ousadas e criativas invenções cênicas. Alguns dos mais qualificados e arrojados espetáculos que estiveram em cartaz no Rio ultimamente podem ser vistos com maior ou menor precisão por este ângulo ${ }^{4}$. Existe inclusive uma nova cena carioca que tenta retomar temas políticos mas se afasta de Brecht, ao absorver o naturalismo dos atores apenas como mais um dos elementos a serem utilizados na estrutura de crítica ou de ruptura do dispositivo da encenação.

Por parte dos artistas do palco experimental, muitas vezes a prática do estilo natural em um espetáculo de linguagem "ousada" ou "contemporânea" pode ser impulsionada e legitimada pela ideologia da atuação pós-dramática ou da performance. A teoria de valorização da opacidade performativa, que pregaria o fim do objetivo de ficcionalizar um personagem, pode abrir espaço ou se misturar ao expediente pasteurizador da indústria audiovisual, na qual os intérpretes são normalmente incentivados por várias circunstâncias,

4 O elefante, Obituário ideal, Conselho de classe, Paralelamente, E se elas fossem para Moscou?, Ricardo III, Síndrome de chimpanzé: esses foram alguns dos espetáculos observados, que cito aqui, ainda que sob o risco de imprecisões e generalizações. Cada um deles se relaciona de maneiras e com gradações completamente diferentes ao desenho que faço dessas tendências gerais, não havendo espaço neste artigo para a discussão profunda dessas peculiaridades. 
principalmente na teledramaturgia do horário das 17 às 21 horas, a "não interpretarem", a viverem seus papéis como se fossem eles mesmos, em um reality show - a se colocarem em cena como as pessoas normais de classe média que são.

É verdade que muitas vezes as encenações tiram proveito de uma descontextualização proposital, criada pela inserção destas figuras medianas em arranjos ou propostas cênicas nada naturais, provocando fricções cujo estranhamento pode estar virando uma marca carioca para a pesquisa de linguagem ${ }^{5}$. Essa tendência e a possibilidade de utilização consciente desse mecanismo por parte dos criadores deve ser objeto privilegiado de investigação desta pesquisa no que diz respeito a estratégias criativas e processos artísticos.

Todavia, também será necessário levar em conta o fato de que este expediente, ao fazer uso de figuras humanas e de técnicas inspiradas ou próximas à padronização da indústria audiovisual, pode estar embutindo um gosto por certo tipo de autorrepresentação, que privilegia a estupefação da figura humana "normal" - com modos burgueses brancos e em geral da zona sul - diante de um mundo desmantelado ou enlouquecido, cuja complexidade está muito além de sua compreensão. Isso explicaria pela via da delimitação sociocultural a (quase) ausência de outro tipo de representação de sujeito nos palcos cariocas. Entretanto, essa é uma explicação parcial, já que tal lacuna de subjetividades não parece ser um fenômeno restrito ao Rio de Janeiro, mas observável em boa parte do teatro produzido e consumido pela classe média brasileira, principalmente a partir do momento em que outros estratos sociais também começaram a se manifestar teatralmente.

Minhas pesquisas foram ainda inconclusivas quanto às causas dessa desconexão de parte do teatro carioca para com realidades sociais que não aquelas, de classe média, dos que em geral o produzem dentro dos teatros públicos. A cidade que começa do outro lado do Túnel Rebouças, que vai além

5 Nos espetáculos de Christiane Jatahy, por exemplo, câmeras preenchem performativamente a cena, ao mesmo tempo que solicitam atuações hipernaturalistas dos intérpretes. Sua ótima acolhida europeia pode esvaziar ou reforçar a hipótese de especificidade carioca deste tipo de dispositivo, a depender do estudo de sua recepção no estrangeiro. Seria o caso de tentar compreender se, lá fora, o imenso interesse provocado por essas instigantes encenações estaria mais ligado a um ineditismo ou a uma identificabilidade junto de alguma tendência internacional consagrada. 
da curva da Avenida Brasil, ou que adentra o interior de qualquer favela; suas opressões, encarceramentos, torturas, chacinas, analfabetismos funcionais e subalternidades parecem ser ao mesmo tempo nosso ponto cego e nosso tabu teatral. Seus estereótipos podem até ser amplamente comercializados pela televisão e pelo cinema desde os anos 1990 (PEREIRA, 2009), mas para os palcos dos teatros públicos do centro e zona sul, que abrigam as experiências cênicas consideradas contemporâneas, essa outra cidade continua em geral invisível, e seus habitantes ainda negados enquanto sujeitos. Essa dificuldade em representar o "outro", que pode provocar a desconexão entre o teatro e a esfera pública da sociedade (BALME, 2014; GUENZBURGER, 2015a), diz respeito aos meios de produção, mas também às possibilidades e limites da inovação estética no âmbito do experimento teatral. Por isso, também faz parte das inquietações que movem a pesquisa no pós-doutorado.

Por sua vez, este aparente paradoxo teatral carioca, formado pela conjunção da inovação cênica com o naturalismo atorial, pode estar em ressonância com o longo diálogo estético que o experimentalismo da cidade mantém com as duas forças sociais que mais influenciam a vida profissional de seus artistas: o patrocínio e a televisão. Pelo menos é isso que sugerem os dados e conclusões levantados até aqui pela presente pesquisa.

Se, pela via da concorrência artística e da libertação dos grilhões da bilheteria, o patrocínio pode estimular a constante reinvenção da cena contemporânea, a televisão poderia, pela via da conformação a um paradigma onipresente de sucesso, "bom gosto" e moderação expressiva, exercer uma barreira a novas experimentações atoriais, chegando a constituir uma tendência de castração criativa ao trabalho do intérprete carioca. Embora a naturalidade em cena possa ajudar o ator na difícil tarefa de se legitimar junto ao público e ao métier de um mercado competitivo e parcialmente parametrado pela normatização audiovisual, corre o risco de retirar desse mesmo artista a capacidade política de criar novas formas corporais para representar o ser humano. $\mathrm{O}$ ator que se rende à padronização do natural teria que delegar essa tarefa ao encenador. Mas será que no teatro a encenação seria capaz de criar, sozinha, novas visões possíveis de humanidade?

A lógica do novo espírito do teatro carioca parece não permitir que o potencial de libertação artística do patrocínio, que atua sobre as amarras cria- 
tivas da encenação, se estenda aos intérpretes. Afinal, quem patrocina os atores e atrizes? No Rio, cada vez mais, os editais públicos financiam espetáculos enquanto empreendimentos individuais de prazo determinado, que assim podem e devem cumprir sua função renovadora de descobrir novos caminhos pela via da encenação. Mas não há por aqui políticas públicas que contemplem a lógica de longo prazo da criação e da sobrevivência dos artistas do palco. Com rendas de bilheterias praticamente nulas, cachês por empreitadas, precários e intermitentes, cada vez mais os atores do circuito das redes públicas de teatro se voltam para seu principal horizonte de profissionalização: a televisão. Algumas exceções conseguem assumir os dois ofícios e, mais raramente ainda, separar bem as suas demandas estéticas diversas, tirando ainda um proveito legitimador e midiático dessa dupla atividade - tal como tinham conseguido anteriormente os atores modernos cariocas que ajudaram a fundar a indústria televisiva no Rio, a partir do exemplo de 1959 de Sergio Britto e Fernanda Montenegro em O Mambembe (GUENZBURGER, 2015b).

No entanto, hoje em dia, o exemplo dos "bem-sucedidos" contemporâneos parece reforçar e legitimar um modelo do caminho de sucesso a seguir, que vai desde o teatro alternativo carioca até o Projac/Globo ou a Record, passando por gradações e variações do mercado atorial, uma vez que a rede teatral da zona sul promete ser ainda o melhor e mais disponível mostruário para contratação de mão-de-obra de bom nível para essas emissoras, sediadas na cidade. E, junto a esta perspectiva real de profissionalização, os exemplos dos que alcançaram o sucesso também ajudam a difundir os modos de atuação necessários para obtê-lo, reforçando assim o caráter paradigmático do estilo a seguir.

Mas a verdade é que a grande maioria dos atores em atividade no Rio de Janeiro compõe a massa semiamadora dos que nunca entrarão para o meio profissionalizado da televisão, a não ser para servirem eventualmente de mão-de-obra de reserva para pequenas "pontas." Dentre estes, há aqueles que, por não desistirem do teatro de jeito nenhum, assumem outras profissões concomitantes ao ofício intermitente do palco. Talvez seja curiosamente nestes casos, nos quais a diletantização poderia significar uma maior liberdade para a pesquisa de novas linguagens atoriais, que o paradigma profissional da televisão acabe se fazendo em geral mais presente. Contida no 
próprio horizonte de expectativas das plateias e dos agentes do meio teatral, a pressão que a estética da atuação televisiva exerce sobre um ator experimental inseguro e à deriva no mercado teatral, ansioso por demonstrar seu profissionalismo, pode acabar representando uma força subliminar e conservadora em seu trabalho.

Essa tendência de conservadorismo formal do ator - que aparece como uma das hipóteses a serem desenvolvidas e verificadas na presente pesquisa de pós-doutorado - pode aumentar ainda mais se houver na plateia um diretor ou produtor de elenco, que estaria ali justamente para avaliar a possibilidade técnica de alguns para trabalharem nos estúdios. Essa difícil medida de profissionalismo inclui carisma, "brilho no olhar", capacidade de empolgar o espectador e, principalmente, saber diluir tudo isso em um jeito natural e cotidiano de falar, gesticular e se mover no palco.

\section{Fundamentação, possibilidades e desdobramentos da hipótese do paradoxo}

Ainda que reconhecendo o potencial inovador da cena carioca e o papel que os diversos fomentos têm neste processo, as hipóteses aqui resumidas partem da premissa de que uma política pública unicamente direcionada a projetos de encenação não atacaria o problema da sobrevivência dos atores e atrizes na cena experimental do Rio. Estes ficariam expostos, portanto, à influência do campo profissional da televisão, cujo paradigma naturalista de atuação acabaria, assim, interferindo fortemente em seu trabalho artístico. Mas esse não seria um movimento de causa e efeito, e sim de diálogo e de influências em ambas as direções. Como vimos anteriormente, os artistas cariocas tiveram, e continuam tendo, maior ou menor participação na formulação das políticas públicas que empurram seu teatro na direção do evento e, mesmo quando não participam, estão optando por se colocarem de acordo com as regras vigentes. De certa maneira, as visões do teatro por projetos, do encenador como empreendedor e do ator multimídia e multimeios parecem fazer parte do imaginário de um novo espírito teatral carioca, capaz de conciliar ideologicamente o experimentalismo teatral à praxis do empreendedorismo. A face artística desse jogo de forças aparece sugerida na hipótese de pes- 
quisa como uma possibilidade esquizofrênica de representações de mundo extremamente criativas e inovadoras em uma cena que poderia ser habitada, ao mesmo tempo, por representações conservadoras e normatizadas do ser humano. Ao seguir o naturalismo da indústria audiovisual e apresentar sua própria condição de classe média como "a" verdadeira natureza humana, o teatro fechado nesse tipo de representação corporal estaria correndo o risco de apagar as lutas sociais e as contingências históricas e culturais que envolvem o surgimento e a manutenção da ordem burguesa, legitimando assim sua naturalização e seu discurso de convergência universal.

O possível caráter conservador de tal pressão, que seria exercida pelo padrão televisivo sobre o ator carioca contemporâneo, é um dos temas mais melindrosos e, talvez por isso mesmo, menos explorados pela crítica e pela pesquisa sobre o teatro. Faltam-nos ainda marcos teóricos seguros para detectar, mensurar ou compreender essas relações. No intuito de investigar e testar essa possibilidade, pretendo aprofundar uma noção atorial que formulei em meu doutorado, utilizando a abordagem da genética teatral. Trata-se do paradigma do otimismo dos personagens, desenvolvido como técnica pelos atores do nosso teatro moderno (GUENZBURGER, 2012b, 2015a) e que apareceu na pesquisa como reminiscência atorial melodramática e como angariador de empatia. Sua incorporação pela atuação moderna brasileira dependente de bilheteria, assim como sua dissimulação na atuação naturalista da televisão, levantou a questão de uma possível função de ligação entre o trabalho do ator na modernidade e a ideologia burguesa de progresso. O otimismo em cena, propagador eficaz da esperança no futuro, poderia ser pensado como elo performático, que uniria diacronicamente o melodrama, o "teatro civilizatório" (ARRABAL; LIMA, 1982) e a telenovela brasileira na tarefa que cada um exerce, a seu tempo e a seu jeito e grau, de mediação ideológica (MARTIN-BARBERO, 1997) e de educação moral para as massas (ARENDT, 2003).

As ideias de mediação e educação, como algumas das funções sociais da arte e do artista teatral, já justificariam a inclusão e o aprofundamento dos estudos de sociologia nesta pesquisa, uma vez que ambas sugerem um encontro entre diferentes estratos sociais, no qual atuam estratégias de aproximação, diálogos e conflitos. Nossa pouca tradição na sociologia da cultura e a ausência quase total de uma sociologia do teatro brasileiro empurraram a 
pesquisa de doutorado para a França, onde estes campos possuem um grande lastro de estudos e concretizações em políticas públicas.

Durante o doutorado, tive a oportunidade de verificar, em estágio sanduíche na Universidade Sorbonne Nouvelle (Paris III), que até hoje as teorias de Pierre Bourdieu estão muito presentes na sociologia da cultura e dos hábitos culturais dos franceses, seja para serem continuadas ou contestadas, levando esta disciplina para a direção dos estudos das interações e delimitações sociais através do gosto (LAHIRE, 2009, 2011; DONNAT, 1994; DONNAT; TOLILA, 2003; FLEURY; SINGLY, 2011; COULANGEON, 2011, 2014; COULANGEON; DUVAL, 2013).

Por outro lado, também pude constatar na França que, curiosamente, os primeiros estudos teatrais a tentarem aproximar a sociologia e as mudanças estéticas recentes no teatro francês têm preterido a propalada ideia de distinção social de Bourdieu em favor do olhar pragmático de Luc Boltanski e Ève Chiapello. Naquelas pesquisas, o atrito entre sistemas de justiça conflitantes, que dividiriam o ambiente teatral em diferentes "mundos" ou "cidades", aparece na origem do atual desencantamento dos vários setores das artes cênicas quanto a seu engajamento, seja este político (HAMIDI-KIM, 2013), ou no mundo do trabalho e do patrocínio governamental à cultura (URRUTIAGUER, 2014).

No caso do teatro carioca do circuito público e experimental da zona sul/centro, a ideia de um novo espírito do capitalismo, enquanto "ideologia que justifica o engajamento no capitalismo" (BOLTANSKI; CHIAPELLO, 2009, p. 39), pareceu, até aqui, bastante apropriada também para começarmos finalmente a discutir a recente adaptação dos artistas a uma nova ordem de produção "por projetos".

Vimos que, na "cidade por projetos" do teatro carioca experimental, os diversos agentes tendem a possuir pouco vínculo entre si no tempo, enquanto se engajam firmes e resolutos na extrema competitividade de um mercado de empreitadas, de certa forma forjado também por eles junto ao poder público e recheado de injustiças ou falhas nos seus sistemas de equivalência. Ali há poucas oportunidades e muitos artistas, e os mais conhecidos têm mais chances que os outros. Esse mercado se caracteriza ainda pela busca de novas linguagens, pela concentração geográfica em torno do centro e da zona sul da cidade, e pela dependência financeira de editais e sistemas curatoriais 
sobrecarregados tais como Sesc, Sesi, algumas empresas estatais, Funarte, fomento municipal, etc.

Mas será necessário procurarmos, também, nesta parte da cena cario$\mathrm{ca}$, a presença dos mecanismos distintivos descritos pela sociologia crítica de Bourdieu (2011) na mistura contemporânea, aqui proposta, de encenação cosmopolita com atuação localizada pelo naturalismo televisivo. Se observados sob a ótica de Bourdieu, tanto o cosmopolitismo do dispositivo cênico quanto a moderação atorial naturalista, redutora do ser humano ao "ser classe média", poderiam hipoteticamente compor a expressão de um palco sem razões urgentes para desejar o aumento de abrangência de sua diminuta plateia, mas, ao contrário, com interesse em delimitar cada vez mais o seu perfil. Mecanismos autorreferenciais da encenação contemporânea, estabelecidos nos últimos 30 anos no Rio, junto com o sistema curatorial que alimenta os patrocínios, poderiam estar conjugados aí com um dispositivo - naturalista - de autorrepresentação corporal de determinado estrato sociocultural, em um processo de distinção social que atravessaria a estética, a produção e o consumo do teatro. $O$ sentimento de pertencimento a uma classe, com todos os compromissos éticos e estéticos que ele pressupõe, ajudaria a alimentar o sistema de legitimações dos diversos mercados de patrocínio. Estas ligações, que se inserem no âmbito geral de uma disputa política, parecem ser um campo importante, ainda a ser estudado, no caso do Rio de Janeiro.

Por fim, é na discussão sobre o sentido do político no interior e no entorno da arte teatral contemporânea, mundialmente dependente de subvenções ou mecenatos, que as tensões entre filosofia e sociologia (NORDMANN, 2007) mais se justificam na presente pesquisa. A influência que a arte pode exercer na "partilha do sensível" - que, segundo Jacques Rancière (2009), definiria previamente quem pode tomar parte da política no mundo - está no cerne de muitos questionamentos sobre as relações entre teatro e sociedade. As novas maneiras de se partilhar o dinheiro público ou privado entre os espetáculos estão certamente implicadas na forma como estes propõem (ou não) ao mundo uma nova partilha do sensível, e, portanto, em como poderão interferir na pólis contemporânea. Essa capacidade de interferência deve ser 
objeto privilegiado de observação, nesta ou em qualquer outra pesquisa, enquanto índice de saúde e desenvoltura teatrais.

\section{Referências bibliográficas}

ARENDT, H. Entre o passado e o futuro. São Paulo: Perspectiva, 2003.

ARRABAL, J.; LIMA, M. A. O nacional e o popular na cultura brasileira: teatro, seu demônio é beato. São Paulo: Brasiliense, 1982.

BALME, Christopher C. The Theatrical public sphere. Cambridge University Press, 2014.

BOLTANSKI, L.; CHIAPELLO, E. O novo espírito do capitalismo. São Paulo: WMF Martins Fontes, 2009.

BOURDIEU, P. A distinção: crítica social do julgamento. Porto Alegre: Zouk, 2011.

COULANGEON, P.; DUVAL, J. (Org.). Trente ans après La Distinction de Pierre Bourdieu. Paris: La Découverte, 2013.

COULANGEON, P. Les Métamorphoses de la distinction: inégalités culturelles dans la france d'aujourd'hui. Paris: Bernard Grasset, 2011.

Classes et culture. La Vie des Idées, 21 mars 2014. Entrevue accordée à Nicolas Duvoux et Igor Martinache. Disponível em: <http://www.laviedesidees.fr/ Classes-et-culture.html>. Acesso em: 25 out. 2014.

DESGRANGES, F.; LEPIQUE, M.; COOPERATIVA PAULISTA DE TEATRO (Org.). Teatro e vida pública: o fomento e os coletivos teatrais de São Paulo. São Paulo: Hucitec; Cooperativa Paulista de Teatro, 2012.

DONNAT, O. Les Français face à la culture: de l'exclusion à l'éclectisme. Paris: La Découverte, 1994.

DONNAT, O.; TOLILA, P. Le(s) public(s) de la culture: politiques publiques et équipements culturels. Paris: Presses de la fondation nationale des sciences politiques, 2003.

FLEURY, L.; SINGLY, F. Sociologie de la culture et des pratiques culturelles. Paris: A. Colin, 2011.

GUENZBURGER, G. O teatro e a estética do fomento. In: CONGRESSO DA ABRACE, VII, 2012, Porto Alegre. Anais... Porto Alegre: Abrace, 2012a. Disponível em: <http://www.portalabrace.org/viicongresso/completos/teatrobrasileiro/Gustavo\%20GUENZBURGER_O_teatro_e_a_est_tica_do_fomento.pdf $>$. Acesso em 4 abr. 2015.

Os datilógrafos e a mecânica do tempo, na cena do tempo mecânico. Cena, Porto Alegre, v. 2, p. 1-21, 2012b. Disponível em: <http://seer.ufrgs.br/cena/article/ view/28026>. Acesso em 4 mar. 2015. 
Rio, cenas decisivas: teatro entre televisão, patrocínio e política. 2015. 228 f. Tese (Doutorado em Literatura Comparada) - Instituto de Letras, Universidade do Estado do Rio de Janeiro, Rio de Janeiro, 2015a.

Fernanda Montenegro em O mambembe: o quelque chose da diva moderna. Sala Preta, São Paulo, v. 15, n. 1, p. 135-155, 2015b. DOI: 10.11606/issn.22383867.v15i1p135-155

HAMIDI-KIM, B. Les cités du théâtre politique en france depuis 1989. Montpellier: Éditions l'Entretemps, 2013.

IBGE. Pesquisa Nacional por Amostra de Domicílios. Rio de Janeiro, 2004.

LAHIRE, B. La fabrication sociale d'un individu. La Vie des Idées, 24 novembre 2009.

Entrevue accordée à Nicolas Duvoux. Disponível em: <http://www.laviedesidees. fr/La-fabrication-sociale-d-un.html>. Acesso em 25 out. 2014

L'homme pluriel les ressorts de l'action. Paris: Pluriel, 2011.

MARTIN-BARBERO, J. Dos meios às mediações: comunicação, cultura e hegemonia. Tradução de Ronald Polito e Sergio Alcides. Rio de Janeiro: UFRJ, 1997.

NORDMANN, C. Bourdieu, Rancière: la politique entre sociologie et philosophie. Paris: Éditions Amsterdam, 2007.

PEREIRA, V. H. A. P. Encenando identidades sociais - reforçando estereótipos? In: PEREIRA, V. H. A. P.; LIGIÉRO, Z.; TELLES, N. Teatro e dança como experiência comunitária. Rio de Janeiro, EdUERJ, 2009. p. 31-41.

RANCIÈRE, J. A partilha do sensível: estética e política. São Paulo: Editora 34, 2009.

SMARTBE; BAYER, L. L'artiste, un entrepreneur? Bruxelles: Les Impressions Nouvelles, 2011.

URRUTIAGUER, D. Les mondes du théâtre: désenchantement politique et économie des conventions. Paris: Harmattan, 2014.

Recebido em 15/08/2015

Aprovado em 09/10/2015

Publicado em 01/07/2016 